\title{
Underwater Noise Monitoring with Real-Time and Low-Cost Systems, (The CORMA Experience)
}

\author{
Paolo Diviacco ${ }^{1, *}{ }^{\circledR}$, Antonio Nadali ${ }^{2}$, Massimiliano Iurcev ${ }^{1}$, Mihai Burca ${ }^{1} \mathbb{C}$, Rodrigo Carbajales ${ }^{1}(\mathbb{D}$, \\ Matteo Gangale ${ }^{2}$, Alessandro Busato ${ }^{1}$, Fabio Brunetti ${ }^{1}$, Lorenzo Grio ${ }^{2} \mathbb{D}$, Alberto Viola ${ }^{1}$ and Nikolas Potleca ${ }^{1}$ (D) \\ 1 National Institute of Oceanography and Applied Geophysics, Borgo Grotta Gigante 42/C, \\ 34010 Sgonico, Italy; miurcev@inogs.it (M.I.); mburca@inogs.it (M.B.); rcarbajales@inogs.it (R.C.); \\ busato@inogs.it (A.B.); fbrunetti@inogs.it (F.B.); aviola@inogs.it (A.V.); npotleca@inogs.it (N.P.) \\ 2 Transpobank, 34012 Trieste, Italy; nadali@tbk.it (A.N.); gangale@tbk.it (M.G.); grio@tbk.it (L.G.) \\ * Correspondence: pdiviacco@inogs.it
}

check for

updates

Citation: Diviacco, P.; Nadali, A.; Iurcev, M.; Burca, M.; Carbajales, R.; Gangale, M.; Busato, A.; Brunetti, F.; Grio, L.; Viola, A.; et al. Underwater Noise Monitoring with Real-Time and Low-Cost Systems, (The CORMA Experience). J. Mar. Sci. Eng. 2021, 9, 390. https://doi.org/10.3390/ jmse9040390

Academic Editor: Giuseppa Buscaino

Received: 19 March 2021

Accepted: 4 April 2021

Published: 7 April 2021

Publisher's Note: MDPI stays neutral with regard to jurisdictional claims in published maps and institutional affiliations.

Copyright: (c) 2021 by the authors. Licensee MDPI, Basel, Switzerland. This article is an open access article distributed under the terms and conditions of the Creative Commons Attribution (CC BY) license (https:/ / creativecommons.org/licenses/by/ $4.0 /)$.

\begin{abstract}
Marine life can be severely affected by anthropogenic underwater noise. This latter increased proportionally to the rise of human activities such as maritime traffic, marine civil engineering works, oil- and gas-related activities or offshore wind farms; so much so that, currently, it can be considered a threat to the environment. Assessing underwater noise requires quite some investments both in personnel and instrumentation. If this is affordable by several governmental and scientific organizations, this cannot be extended straightforwardly to all research initiatives or to developing countries. In addition, time and geographic coverage of monitoring can also be significantly limited by the costs of multiple installations. We explore the possibility to use a solution based on off-the-shelf and low-cost technologies combined with a scalable infrastructure developed with open-source tools only. The perspective to avoid proprietary solutions allows great flexibility in extending the current paradigm toward real-time transmission, processing, and web-based data access. Our solution has been deployed at sea in November 2020 and is providing data continuously ever since. First results from the analysis of these data allowed us to highlight several interesting abiotic and anthropogenic temporal patterns.
\end{abstract}

Keywords: underwater noise monitoring; low cost; real time; wireless; masking; Marine Strategy Framework Directive

\section{Introduction}

Marine species heavily rely on sound to relate with the environment [1]. Sound is critical to foraging, communication, predator avoidance, and general spatial orientation [2].

Following the Marine Strategy Framework Directive (MSFD) of the European Parliament and Council [3], sound that causes negative effects is defined as noise, and indeed, exposure to underwater acoustic noise affects marine life.

The effects of underwater noise on marine life spans a large range of phenomena [4] of which a subset rise to the level of deleterious ecological significance in terms of longterm population consequences [5]. The impact of underwater anthropogenic noise spans issues such as behavioral responses [6,7], masking [8-10], hearing loss [4], physical, and/or physiological effects up to death [11]. In addition, in order to monitor and forecast the impact that underwater noise has, it is very important to consider the overall ecology of affected habitats [12].

While there has been a prevalent focus to study the effects of noise on marine mammals [13-15] and some degree of protection, in this case, has been already implemented [16], increasing attention is being paid to fishes and invertebrates that have different hearing physiology and behavior [12]. For example, while a fish ear does not have a comparable frequency analyzer like the cochlea in mammals and birds [10], they can be more sensible to particle motion rather than sound pressure [12]. 
A large part of underwater noise can be associated with human activities, implying that their rapid increase can severely harm marine life.

Activities related to oil and gas extraction, such as geophysical surveys using airgun sources, deserve a lot of attention [17,18]. Offshore wind farms are rapidly expanding [19], and tidal turbines are also of concern [20]. To mitigate the impact of such activities, marine mammal observers (MMO) are employed to collect behavioral and species identification data. This is a costly procedure that has also an impact on human health [21].

The most ubiquitous and pervasive source of anthropogenic noise in the oceans, however, are commercial ships [22]. According to Frisk [23], the growth of the world fleet and gross tonnage since World War II shows an exponential expansion rate, while marine traffic has increased four-fold over the past 20 years [24]. It has been estimated that the growth in traffic mirrors a growth in ambient noise as high as $3 \mathrm{~dB}$ per decade [25].

Underwater radiated noise (URN) produced by ships is generated mostly by their propulsion system, which, while generally peaking in a range of frequencies below $200 \mathrm{~Hz}$, also emits considerable energy at higher frequencies [26]. Noise is produced by propeller cavitation that generates bubbles that grow, vibrate, and collapse. Cavitation noise increases with vessel speed, size, and load [27]. The engine and generators onboard can also produce noise that is transmitted through the vessel hull even when the ship is docked or anchored in a bay.

The sound field observed at a certain distance from a specific source depends on the source characteristics and the medium in which it propagates. Moving away from the source, sound waves attenuate according to the conditions of the environment [14]. Ship-traffic-related URN can be modeled in order to reconstruct the sound field in a certain area [28]. This can be done starting from the radiated field of those sources whose characteristics, position, speed, etc., are known. Position and speed can be extracted from the automatic identification system (AIS) that is compulsory within the International Maritime Organization (IMO) International Convention for the Safety of Life at Sea (SOLAS) for vessels with 300 or more gross tonnage [29]. In addition to large commercial ships, there is a considerable variety of other types of boats that produce underwater noise such as, for example, recreational boats, ferries, fishing vessels, or dredges. Each of these classes of boats have different source characteristics and levels that can also vary quite considerably from boat to boat within the same class. Not many of them offer AIS, while some of them can decide to turn off their transceivers, meaning that they eventually cannot be included in the model. The reconstruction of a numeric model of the acoustic field in an area therefore largely depends on the availability of information on the sources and the environment. Where there are limitations on the availability of this information, the reconstructed model is biased.

The MSFD directive mandates that the European Member States implement strategies toward a good environmental status (GES) in the European seas. From the perspective of monitoring underwater ambient noise such as that from URN, it is necessary to assess the 11.2.1 indicator, which is described through the average values of sound pressure (re $1 \mu \mathrm{Pa}$ RMS) over a year, in the two one-third octave bands centered on 63 and $125 \mathrm{~Hz}$ [30]. Passive acoustics monitoring (PAM) systems allow underwater acoustic data to be acquired and analyzed from this perspective [31].

\subsection{Objectives}

The main aim of this work is to explore the possibility of developing a real-time low-cost PAM system tailored to assess anthropogenic noise in marine environments. Current costs for commercial solutions range from $\$ 5000$ to $\$ 30,000$, while our target cost is approximately $\$ 500$. The requirement to reduce costs at minimum has been adopted in order to achieve several ambitions: namely, (i) the possibility to deploy a large number of sensors in order to validate numeric models of the URN acoustic field over large areas; (ii) the possibility to set up PAM systems where large investments are not possible or in developing countries; (iii) the possibility to have an open system that can be improved and 
extended following an open-source approach, and (iv) the possibility to run the system with very low power consumption.

In order to understand the problems and limitations of the proposed system and to devise solutions to overcome them, we deployed a first prototype of the system on a buoy in the Gulf of Trieste. The system underwent several stress tests from extreme weather conditions to network and power interruptions.

A very important objective of this work was also to highlight whether the proposed system would be able to record and allow the identification in the recordings of possible abiotic and anthropogenic temporal patterns.

\subsection{The Development Path}

Several commercial solutions are already available that for sure provide high performance and reliability while solving most of the abovementioned tasks; however, they tend to both remain in a proprietary ecosystem and to be very expensive. This means that all the ambitions listed above can only hardly be met. In fact, aiming at having multiple recording platforms means increasing the costs high above the average available budgets, while it would be very difficult for a nonmajor investor to request specific tuning of the system to address emerging needs such as, for example, connectivity with devices from other manufacturers or open formats or links to specific repositories.

Following Parijs et al. [32], upon the possibility of having immediate or delayed availability of data, PAM systems can be divided in two main classes, namely real-time or archival. In addition, they can be built upon different deployment technologies such as, for example, free-drifting, moored, or towed ones. The combination of class and deployment technology define each system setup.

Archival free-drifting systems follow the paradigm proposed for example by [33]. Archival moored systems are structured similarly to those proposed by [31,34-36]. These are generally battery-powered devices that record and store acoustic data internally. Depending on data storage capacity of the device, recording bandwidth, and sampling regime, recordings can be obtained over extended periods of time; after which, they are retrieved, and the data analyzed.

A possible real-time monitoring implementation could be based on data acquisition surveys, or repeated surveys, at specific positions [33]. This approach is able to provide useful information immediately during the survey but has the important drawback that no information is made available outside the planned acquisitions.

Another approach of real-time monitoring is based on cabled seafloor technologies. Initially, these have been developed for military surveillance, but, currently, several large initiatives, such as the NEPTUNE Canada Ocean Observatory [37] or the European Seas Observatory NETwork (ESONET) such as the Antares [38] or the KM3NeT [39] facilities, moved the focus onto scientific themes, with emerging applications also in bioacoustics.

Cabled observatories can take advantage of several benefits, among which are the availability of direct power supply and the possibility to transfer data via a wired link that allows high bandwidth and throughput. Of course, such settings need large investments that can be supported by major governmental and research institutions only.

An alternative approach to cable communication is to have data sent over a wireless network [40]. Radio frequencies (RF) is widely used in terrestrial wireless communication due to its high transmission rate and accuracy, while water has very high energy absorption so that it can transmit over a short range only [41]. Acoustic communication can be used in water since it suffers from relatively low absorption over long-range links; however, it also has many limitations such as low speed, high latency, and low bandwidth. In addition, it is too much influenced by variations in salinity temperature and density of the medium [42].

Noncabled PAM systems need ways to provide for powering the electronics. Battery packs can be a solution but need either regular maintenance or substitution every few days, which is a substantial cost, either reducing the length of recording and transmission, which means sampling the designated period therefore reduces the amount of information made 
available. Solar power with buffer batteries reduces these costs drastically, while allowing one to extend the temporal coverage of data to continuous recordings; wind power can be interesting but at the risk of introducing noises in the recordings.

\section{Materials and Methods}

\subsection{The Monitoring System}

As mentioned above, the aim of this work was to develop a low-cost, real-time, noncabled PAM system that could cover the whole spectrum of activities related to underwater noise monitoring. To reduce costs at minimum, in setting up the acquisition system, we used off-the-shelf electronics only, and we developed all software using open-source tools only.

In developing the acquisition system, two possible strategies can be implemented and namely (i) local processing of time series where recording is made, in order to transmit data products only, or (ii) transmission of the full-time series. There are advantages and disadvantages in both cases:

If local processing is chosen, data products are files with rather small size, which means that it would be possible to use low bandwidth transmission technologies such as, for example, LORA-WAN. This has a bandwidth in the range between $0.3 \mathrm{kbit} / \mathrm{s}$ and $27 \mathrm{kbit} / \mathrm{s}$, but very importantly, notwithstanding the fact that its signal can easily reach long distance ranges, its power consumption is very low.

On the other hand, a very important disadvantage of this solution is that the time series are lost, meaning that possible future extensions of the system such as, for example, real-time acoustic detection of marine species $[32,38,40,43]$ would not be possible.

The solution based on the transmission of the full time series, of course, overcomes these limitations, so that we decided to focus on this second strategy. In this case, the time series are digitized remotely offshore, and there, they are temporarily cached and passed to the transmission system. Once received, they are stored and processed onshore in the lab.

In designing the system, starting from the very basic need to quantify MSFD indicators, we sought to extend as much as possible the range of the frequency spectrum of the recordings. This has to be carefully considered as large frequency spectrums can be problematic in transmission, since they require large bandwidth. In this perspective LORA technologies cannot be used any more while it is necessary to switch to other technologies such as 3G/4G GSM mobile technologies. These are the most common and reliable wireless data transfer technologies available worldwide, with a theoretical distance ranging up to $30 \mathrm{~km}$ from the base station. While 3G technologies have a $2000 \mathrm{kbps}$ nominal bandwidth considering a single connection to the base station, $4 \mathrm{G}$ extends the bandwidth 10 times, although nowadays, the carriers are very busy with commercial traffic. An estimate of the available bandwidth to rely upon could be approximately $800 \mathrm{kbps}$, which translates into a realistic $5 \mathrm{Mb}$ of data transfer per minute.

Considering the limitations imposed by the connectivity, we were then able to define the range of the audio frequency spectrum that the system would be able to acquire and transmit to a maximum of $20 \mathrm{kHz}$. This value is defined considering $41 \mathrm{KHz}$ sampling rate and 16 bit A/D single channel conversion which produces approximately the abovementioned $5 \mathrm{Mb}$ block of data every minute. The identification of this spectrum range confirms the possibility to use off-the-shelf electronics available for high-fidelity music listening. These devices focus on the human hearing spectrum range which tops at $20 \mathrm{kHz}$, are cheap and reliable, have low power consumption, and can be connected via USB to any small single-board computer for power supply and data transfer.

After an analysis of the market, we have chosen a set of hardware components that could correctly represent the issues that can be encountered within the perspective mentioned above, highlight their limitations, and allow us to propose possible ways to overcome them. This of course should not be considered an endorsement for any particular firm or model, since other hardware can be used with similar results, and in the future better solutions will for sure appear. The chosen hydrophone was an Aquarian 
Scientific AS-1 preamplified Hydrophone connected to a Shure X2u digital audio interface that also provides $48 \mathrm{~V}$ phantom power. The Shure interface is connected via USB interface to a Raspberry Pi 3 B+ board that is connected to a Teltonika RUT 955 modem transmission system.

The Raspberry Pi board has three main tasks: namely, (i) to convert the audio files recorded by the USB digital audio interface to $16 \mathrm{bit}, 44 \mathrm{kHz}$, mono, WAV PCM files using soX [44], (ii) to send data via FTP to the storage system, and (iii) to monitor the system and the Raspberry performance (CPU usage, RAM available, and internal temperature) and the overall power consumption every 5 min. Every task is managed by an independent Bash script which starts at boot device and runs forever.

The length of recordings has been set to $10 \mathrm{~min}$ because, after some tests, this resulted in a good tradeoff to optimize caching, transmission, data processing, and event representation.

Data transmission is the primary source of power consumption, meaning that running the system on batteries only soon results in battery drain. An external power supply is preferable.

The whole acquisition system can be easily packed into a waterproof $30 \times 30 \times 20 \mathrm{~cm}$ box. Considering its small dimensions, it can be installed easily on any platform able to provide the necessary powering.

The total cost of the acquisition hardware is approximately around $\$ 500$.

\subsection{The Deployment Area}

The Gulf of Trieste, with $18 \mathrm{~m}$ average depth, is the area (approximately $500 \mathrm{~km}^{2}$ ) encompassed by the shore line of the northeasternmost part of Italian peninsula and Slovenia bordered by the virtual line between Grado (IT) and Piran (SLO) (20 km length) [44,45] and isolated from the rest of the Adriatic by a sill, from Grado to Salvore peninsula [46] (Figure 1).

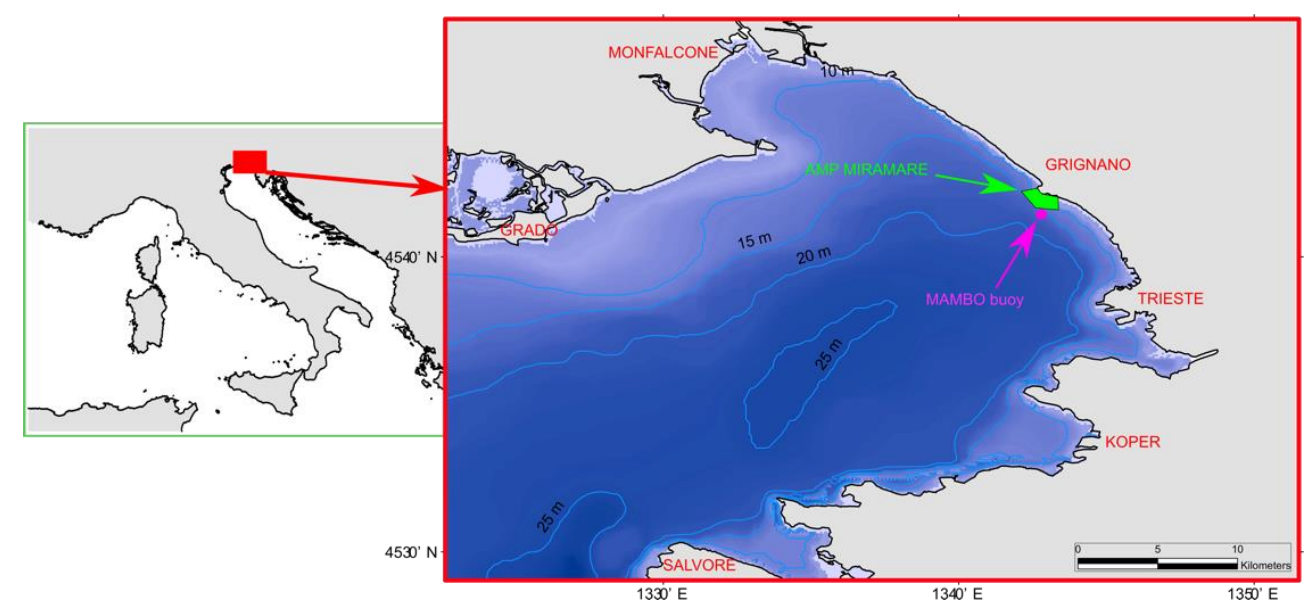

Figure 1. The Gulf of Trieste.

The area is influenced by the Isonzo River discharges which contribute to about $90 \%$ of the freshwater inputs [47]. The area is characterized by a sedimentation that started with the onset of the Holocene transgression and consists in marine sediments originating in the Friuli plain depositing on an erosive surface of the late Pleistocene [48,49].

The hydrodynamics of the Gulf is driven by winds (southeasterly Scirocco and northeasterly Bora), tides, and water masses exchanges with the Adriatic Sea [50].

The Gulf of Trieste hosts the WWF-Miramare Natural Marine Reserve (in green in Figure 1). Since 1979, this site has been declared a marine protected area and represents the only completely protected area, in the Italian part of the Gulf of Trieste, sheltered from all direct human activities and boat traffic.

The Marine Reserve of Miramare is very peculiar in comparison to other more remote Mediterranean marine protected areas, since the level of human presence around it is 
extremely high [9]. The main port of the city of Trieste is approximately $8 \mathrm{~km}$ far from Miramare and is a very active port, with a total throughput of approximately 50 million tons, cargo, ferry, and cruise traffic. In addition, the Miramare Marine Protected Area is located close to a touristic port that is very active during the summer period with a high recreational boat traffic. Such conditions are common to many other more distant touristic harbors on the Italian, Slovenian, and Croatian sides of the Gulf.

The area is densely populated by different fish species; some of them are known to be vocal, namely fish species belonging to Gobidae, Sciaenidae, and Pomacentridae families [9,51] and crustaceans such as snapping shrimps [1], while occasionally mammals are also reported to visit the area [52].

\subsection{The Observatory Platform}

The developed system was installed on the OGS MAMBO-1 buoy located within the Miramare Marine Protected Area at the beginning of November 2020 and has continuously transmitted real-time data ever since (Figure 2).
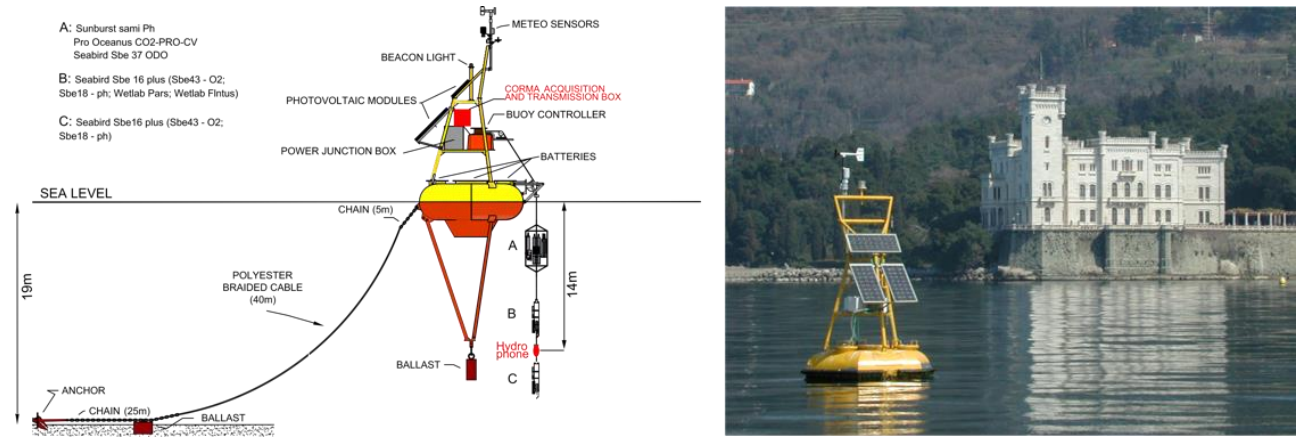

Figure 2. The observatory platform.

The MAMBO-1 buoy is a multi-instrument platform for ambient meteo-marine monitoring in coastal areas, developed by OGS [53]. It is also used as a test site for the development and testing of new sensors, instruments, and technologies. The body of the buoy is made up of a floating hull in stainless steel AISI 316, an aluminum tripod $3 \mathrm{~m}$ high, and a stabilization system under the surface made up of three steel rods joined to a $150 \mathrm{~kg}$ ballast. The bottom is at about $19 \mathrm{~m}$ depth, while the hydrophone is deployed at $14 \mathrm{~m}$ depth. The mooring of the buoy is made on three points placed at $120^{\circ}$ : each one realized by an anchor and a rope about $40 \mathrm{~m}$ long plus $20 \mathrm{~m}$ of chain. The buoy is equipped with six solar panels, mounted on support brackets and oriented to the south with an inclination of about 45 . Each panel is connected to a charge controller and the latter to a battery pack consisting of two rechargeable lead accumulators (12 v-70 Ah) connected in parallel. With this solar charging configuration, the system has autonomy of 5 days in the worst case without sun, while it would fully recharge in two sunny days.

\subsection{Data Processing and Web Based Visualization}

The transmission technology adopted allows it to transfer recorded data directly into a NAS storage server from where it is submitted to data processing and dissemination.

Timing is based on GPS. This is acquired directly by the transmission modem that acts also as an NTP server for the acquisition board.

The current implementation is based on a Linux server, deployed on a virtual machine running PHP and Python scripts that periodically collect and process the raw audio files. Metadata is stored into a Postgres database, while different data products (such as spectrograms) are stored as JPG files on the storage system.

A web frontend, based on Apache and HTML + CSS + PHP + JavaScript, provides a friendly and interactive user interface with a complete view of the acoustic monitoring 
activity. A basic authentication layer (with username and password) protects all sensitive data from unauthorized web use.

The scripts are executed every five minutes, in order to ensure near real-time information. The total delay of the system from acquisition to visualization is less than $10 \mathrm{~min}$ after the end of every 10 min chunk of audio recording.

The dataflow starts with a search for new audio files (not yet processed) on the storage server. All new files are copied to the processing server and if the buoy system has had a temporary transmission blackout, all the missing files are readily downloaded, filling the gaps. Every new audio file (a 10 min WAV audio file, marked by the start time in UTC and a buoy ID) is then processed by Python scripts developed within the project and based on standard NumPy and SciPy libraries only. Third octave SPL values are stored into the database, together with all metadata; spectral analysis images are stored into the filesystem.

The raw WAV audio files are analyzed through different steps. The signal is sliced into $500 \mathrm{~ms}$ intervals, with an overlapping of $100 \mathrm{~ms}$. At every time interval $\mathrm{t}_{\mathrm{j}}$ a Hann window function is applied, in order to prevent spectral leakage, the FFT is calculated in order to produce a narrowband spectrum.

This is followed by the conversion into $\mathrm{dB}$ and the application of the spectrum correction (function of frequency $f_{i}$ ) to compensate for the filtering effects due to the difficulties in setting the gain and the possible frequency dependent effects (see Section 3.1) (Figure 3).

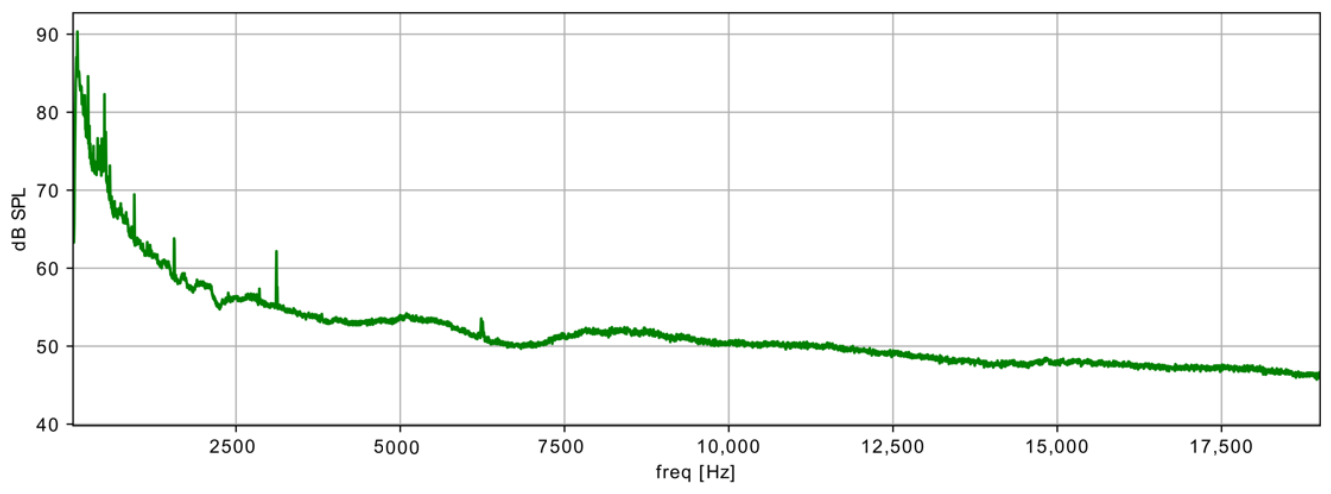

Figure 3. Corrected narrowband spectrum $(\mathrm{dB}, \mathrm{re} 1 \mu \mathrm{Pa})$ of a recorded $10 \mathrm{~min}$ time series produced automatically by the system.

Then applying:

$$
\mathrm{L}_{\mathrm{ij}}=20 \log 10\left|\mathrm{FFT}_{\mathrm{ij}}\right|-\operatorname{cal}\left(\mathrm{f}_{\mathrm{i}}\right)
$$

We obtain $\mathrm{L}_{\mathrm{ij}}$ which is the sound pressure level (SPL) in $\mathrm{dB}$, relative to $1 \mu \mathrm{Pa}$, for the time interval $t_{j}$ and the frequency $f_{i}$. The matrix $L$ directly produces the spectrogram chart (Figure 4).

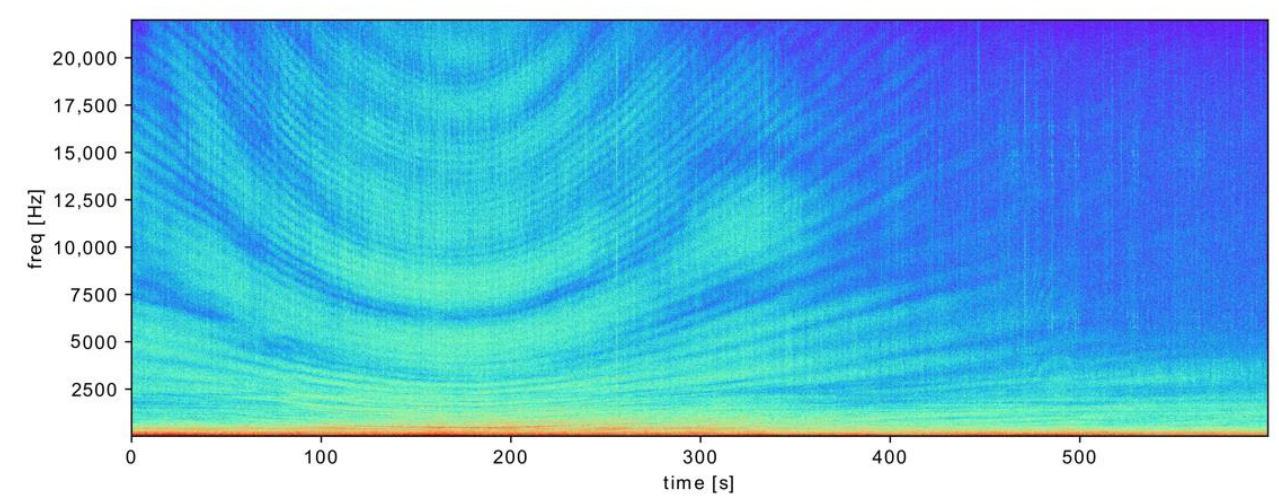

Figure 4. Spectrogram of a $10 \mathrm{~min}$ recording produced automatically by the system; it is possible to notice the movement of a noise source (very likely a small boat). 
According to Welch's method [54], the columns can be averaged, and the resulting vector is a single narrowband spectrum for the whole period

In order to aggregate several narrowband values to a wider band, we use the following relation:

$$
\mathrm{R}_{\mathrm{j}}=10 \cdot \log _{10}\left(\sum_{\mathrm{i}} 10^{\frac{\mathrm{L}_{\mathrm{ij}}}{10}}\right)
$$

to obtain a graph of SPL versus time (Figure 5).

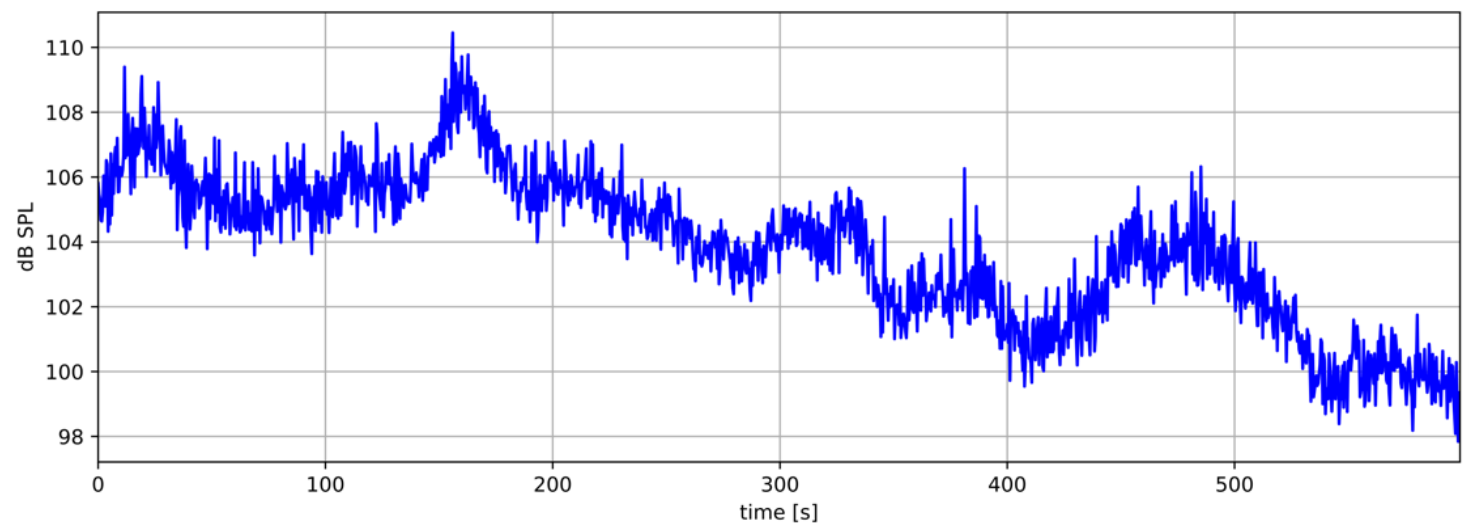

Figure 5. Graph of sound pressure level (SPL) as a function of time produced automatically by the system.

Combining the narrowband spectrum into ANSI third octave bands and averaging on the whole $10 \mathrm{~min}$ period, we obtain the one-third octave bands values (Figure 6).

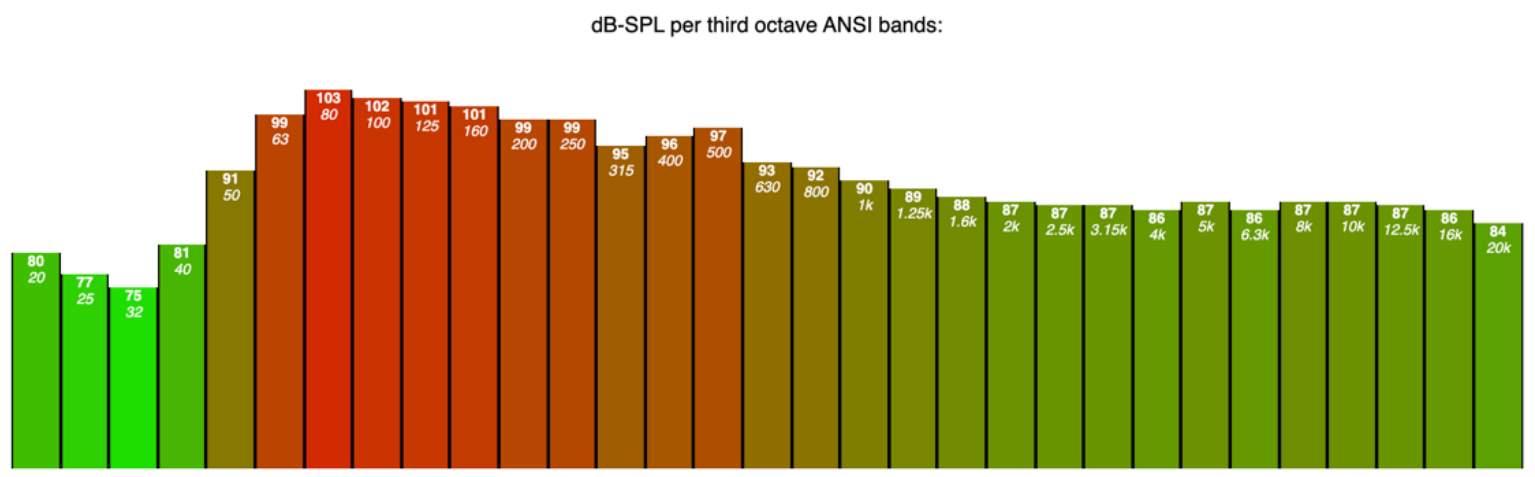

Figure 6. SPL per one-third octave band produced automatically by the system.

In order to provide a first glance of third octave levels, building on previous experiences $[55,56]$, by means of chromatical and numerical information as a function of time of the day, we developed a web frontend (Figure 7) that can be accessed at [57].

The web user can display all the detailed graphs, download the raw audio files, and directly visualize and listen to the audio online after authorized registration and login. 


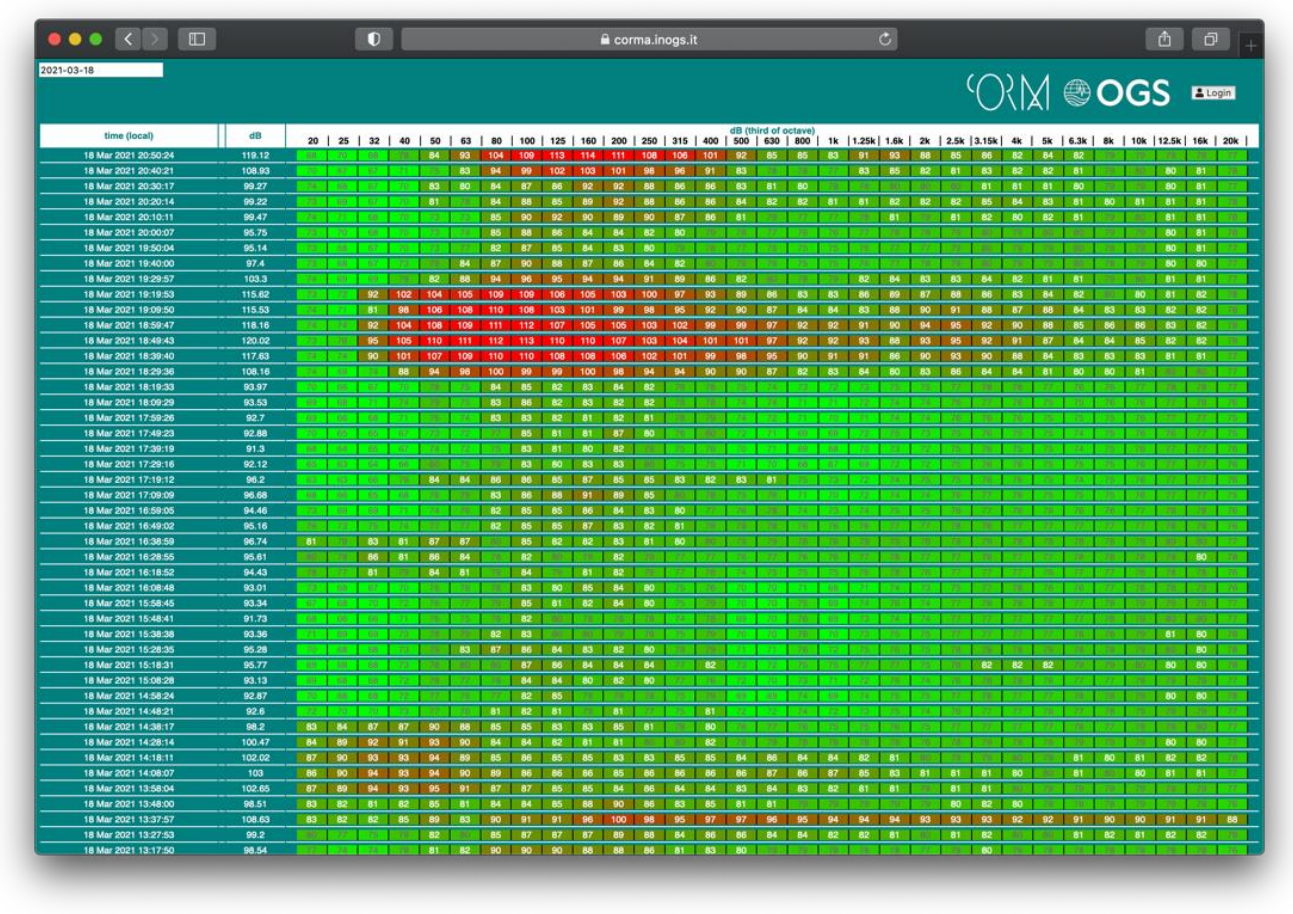

Figure 7. The web portal (https:/ / corma.inogs.it (accessed on 6 April 2021)) [57] where the one-third octave band values are graphically represented in real time. It is easy to identify periods where the level of noise is higher and also in which frequency range.

\section{Results}

\subsection{System Performance Results}

Hydrophones calibration should follow IEC 60565:2020 [58] specifications. Several methods can be used such as a commercial pistonphone at $250 \mathrm{~Hz}$, coupler reciprocity chamber [59], or more complex methods [60,61]. Besides proper calibration in the laboratory, the authors of [62] highlight the importance of the effects that are due to deployment suggesting that in situ corrections are to be considered as well. Contrary to most of proprietary marine acoustic recording solutions, where intermediate steps are hidden to users, they can directly read the actual SPL values in $\mathrm{dB}$ re $1 \mu \mathrm{Pa}$; In the case of low-cost systems like the one we built, since it results from piping different parts, it is necessary to carefully verify the final results of measurements. This is particularly important in order to assess underwater noise in the perspective of the MSFD descriptors and to pave the way for further developments.

Following the path of the signal through the whole acquisition system we can consider several steps. The hydrophone transforms the relative pressure $(\mathrm{P} / 1 \mu \mathrm{Pa})$ into voltage $(\mathrm{V})$, then a preamplifier applies some gain, then the input preamplifier of the sound card applies another gain, and finally the electric signal is sampled and transformed into a 16 bit number. Within the considered range $20 \mathrm{~Hz}-20 \mathrm{kHz}$, all these steps are either linear or, in the worst case, with a limited frequency distortion, but we assume the phase distortion to be negligible. The latter consideration relies on technical specifications of the components. Assuming the lack of phase distortion, the concatenation of the transfer functions would be without phase distortion too, producing a shift in $\mathrm{dB}$ depending only on frequency.

To understand this offset we used the difference between the calculated $\mathrm{dB}$ and the values provided by a high-quality calibrated system in order to evaluate the corrective constant.

The low-cost hydrophone used has been calibrated at $250 \mathrm{~Hz}$ by the producer with $\mathrm{a}+/-2 \mathrm{~dB}$ accuracy and has a receiving sensitivity: $-208 \mathrm{dBV}$ re $1 \mu \mathrm{Pa}(40 \mu \mathrm{V} /$ Pascal $)$. Problems rise in the following steps of gain and digitization. To keep costs at minimum, as mentioned above, we used a standard digital music audio interface. These have limitations in accurately setting the gain. Musicians in fact only very seldom care about measuring the 
output of their instruments or microphones, while they are more interested in the fact that their instruments fit the dynamic ranges of the rest of the recording or amplification system. At the same time, standard music audio USB interfaces are tailored for human hearing which at best ranges from $20 \mathrm{~Hz}$ to $20 \mathrm{kHz}$. Very low frequencies can be problematic for them and anyway not heard, meaning that such audio interfaces often tend to apply a low-cut filter to avoid unwanted energy into recording.

The carefully calibrated proprietary system is a seamless set of a Brüel \& Kjær Type 8104 D 500 hydrophone connected to a Brüel \& Kjær input module LAN-XI 102.4 kHz Type 3052 with recording parameters set to exactly match those of the low-cost system.

The two systems have been deployed side to side at the same location for simultaneous recordings of two kinds of signals, namely: (i) ambient sounds, meaning sounds that would be present in the absence of any specified activity (ISO 18405 ([63], p. 18405)) and (ii) a common source consisting of an engine from a nearby boat that was anchored in the bay and that we were able to control remotely. Results of the comparison can be seen in Figure 8 where the spectra recorded by the two systems are juxtaposed.

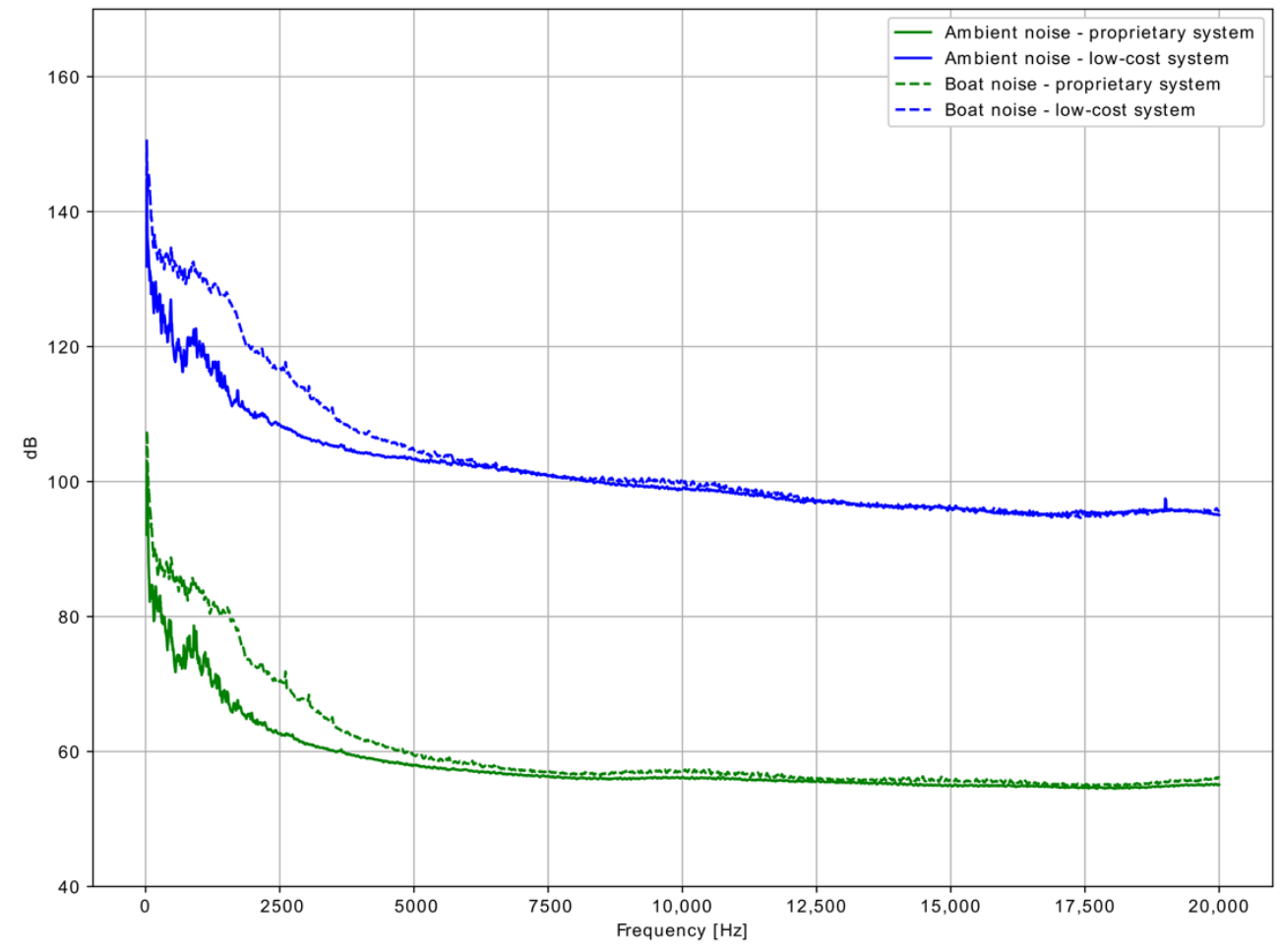

Figure 8. Comparison of spectra obtained from the reference proprietary system (green) and the low-cost system (blue) in the case of ambient noise (solid line) and a known noise source: a boat (dashed line); the difference in gain is due to the difficulties in controlling the gain of the low-cost sound interface.

The differences between them are assumed to correspond to the filtering effects of the low-cost acquisition system (Figure 9). It can be noted that corrections are negative, meaning that the low-cost system tends to overestimate the SPL. This is likely due to the difficulties in setting the gain of the digitizer, meaning that an excessive gain has probably been applied. The filter can then be reversed and applied to the CORMA recordings in order to obtain approximately the SPL that could have been recorded using the proprietary system. In this case, a direct application of a reverse filter would probably be not reasonable. The filtering effect, as can be seen, is frequency dependent and not exactly the same in the case of ambient noise and that of the boat engine. To overcome this, we decided to apply a regression on the available spectra and study two scenarios, namely linear regression and polynomial regression. In the first case, the errors can be of the order of $6 \mathrm{~dB}$, while in the 
latter case errors are less than $+/-2 \mathrm{~dB}$, which is the nominal accuracy of the hydrophones as reported by the manufacturer.

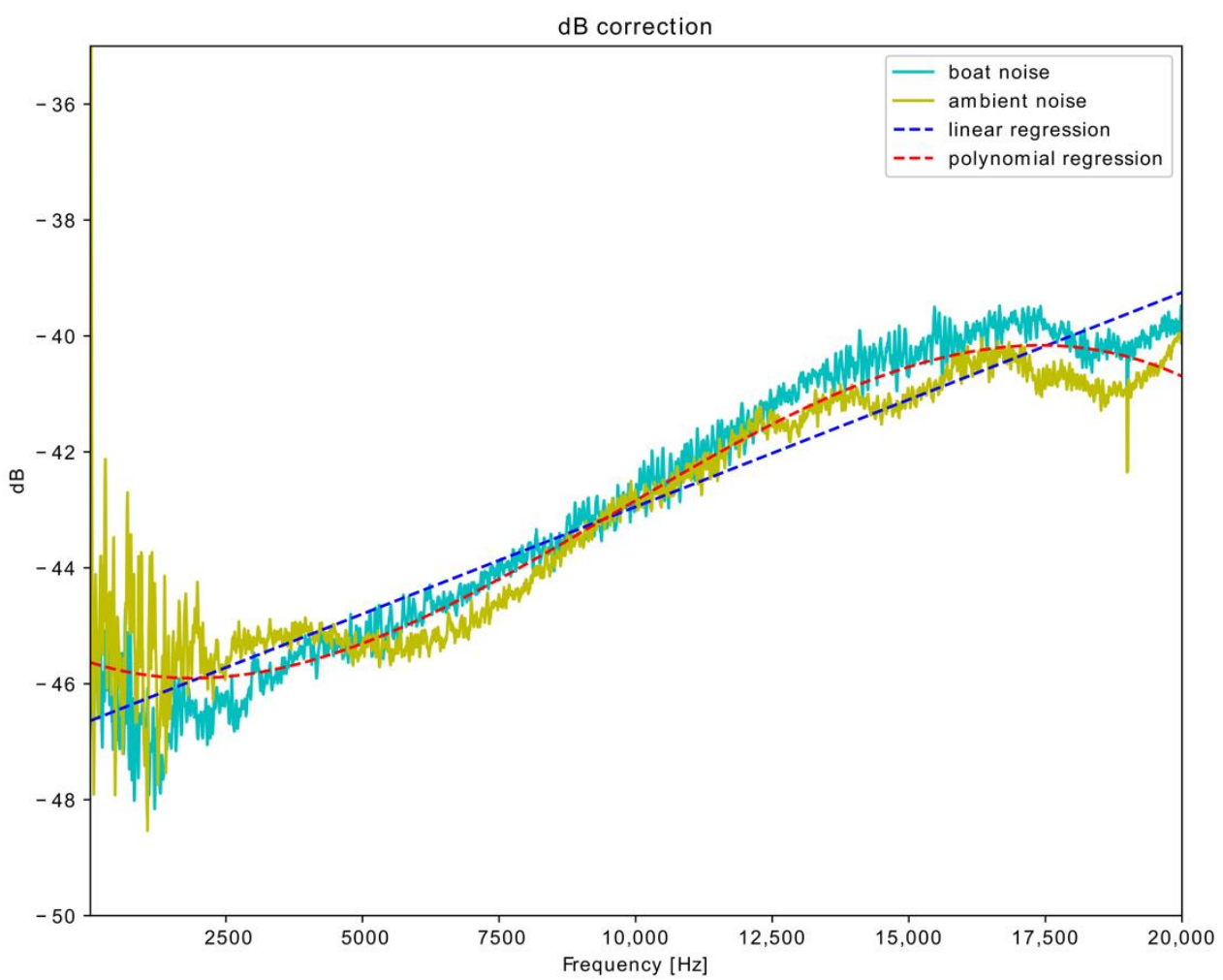

Figure 9. Plot of the corrections to be applied to the spectrum of the data from the low-cost system in the two cases: boat noise (cyan), ambient noise (green), a linear regression (blue), and polynomial regression (red) are identified and applied automatically to the recordings.

Data correction is then performed, using the polynomial regression model only once. Data have been copied into the processing server onshore (see Section 2.4).

\subsection{First Monitoring Results}

The acquisition system was deployed on 20 November 2020. We concentrate our analysis on the three months period starting 21 November 2020 (Saturday) and ending 13 February 2021 (Saturday).

During this period, the transmission was continuous except for a small interval between 5 February 2021, and 6 February 2021, when we experienced network issues. This suggested us to add an SD card to the acquisition system where, in case of connectivity problems, data can be stored temporarily until the link is again made available. All data are then flushed with a delay but with no loss. Later tests, when we deliberately shut the connection down, confirmed that this strategy is successful.

During these three months period of wintertime, notwithstanding the weather was often cloudy and the daylight was reduced, we experienced no issue in power supply.

The SPL recorded in the period can be seen in Figure 10. Each graph shows an SPL graph as a function of date for a period of two weeks.

In the perspective of the MSFD and to compare our results with experiences from other authors, we analyzed separately the one-third octave bands of the spectrum of the recordings. Figure 11 compares the minimum, maximum, average, and the standard deviation values as a function of day for the cumulative, 63, 125, and $500 \mathrm{~Hz}$ central frequency bands of the recording in the designated range of dates. 

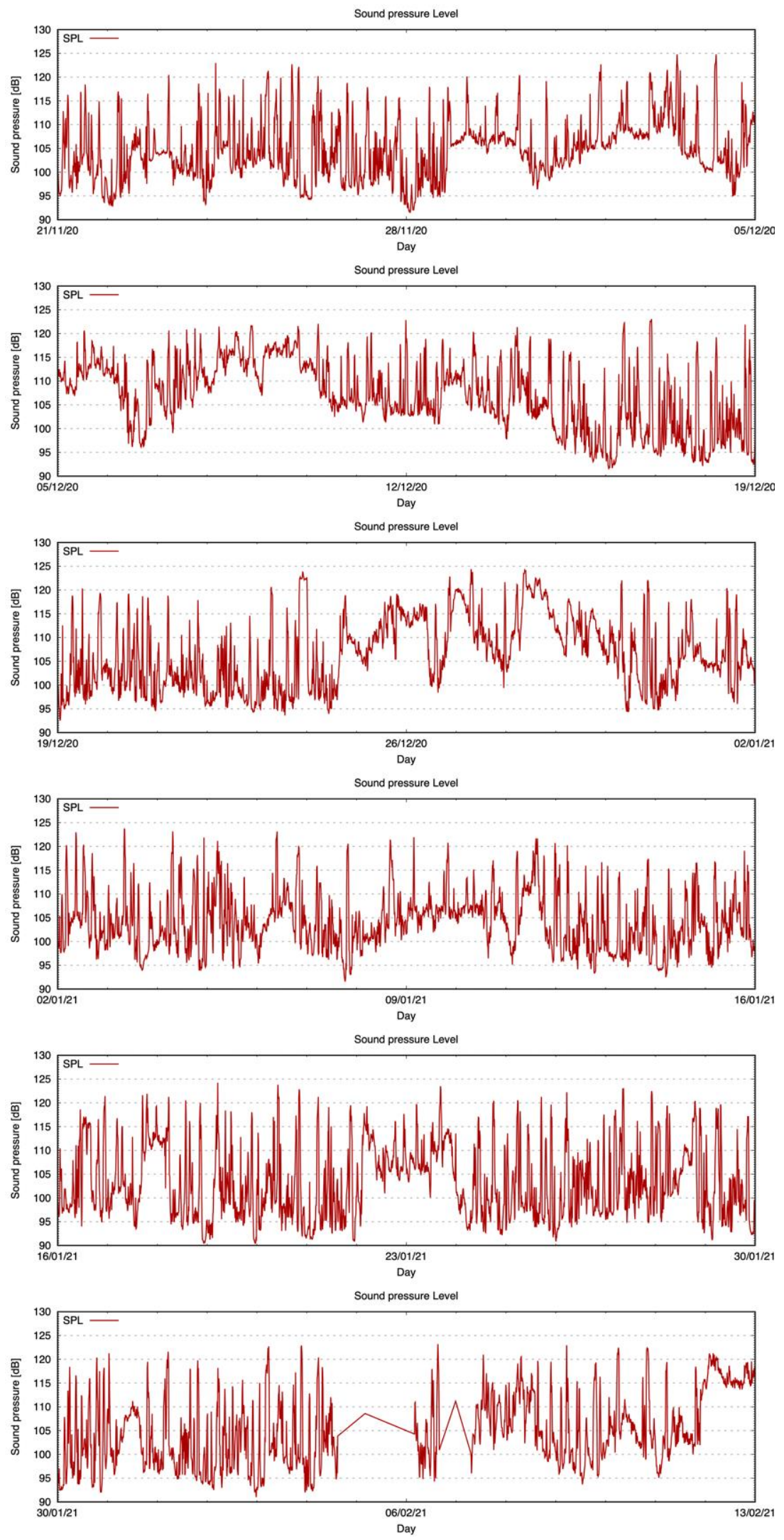

Figure 10. SPL time series between 21 November 2020 and 13 February 2021, each graph shows recordings during two weeks. 

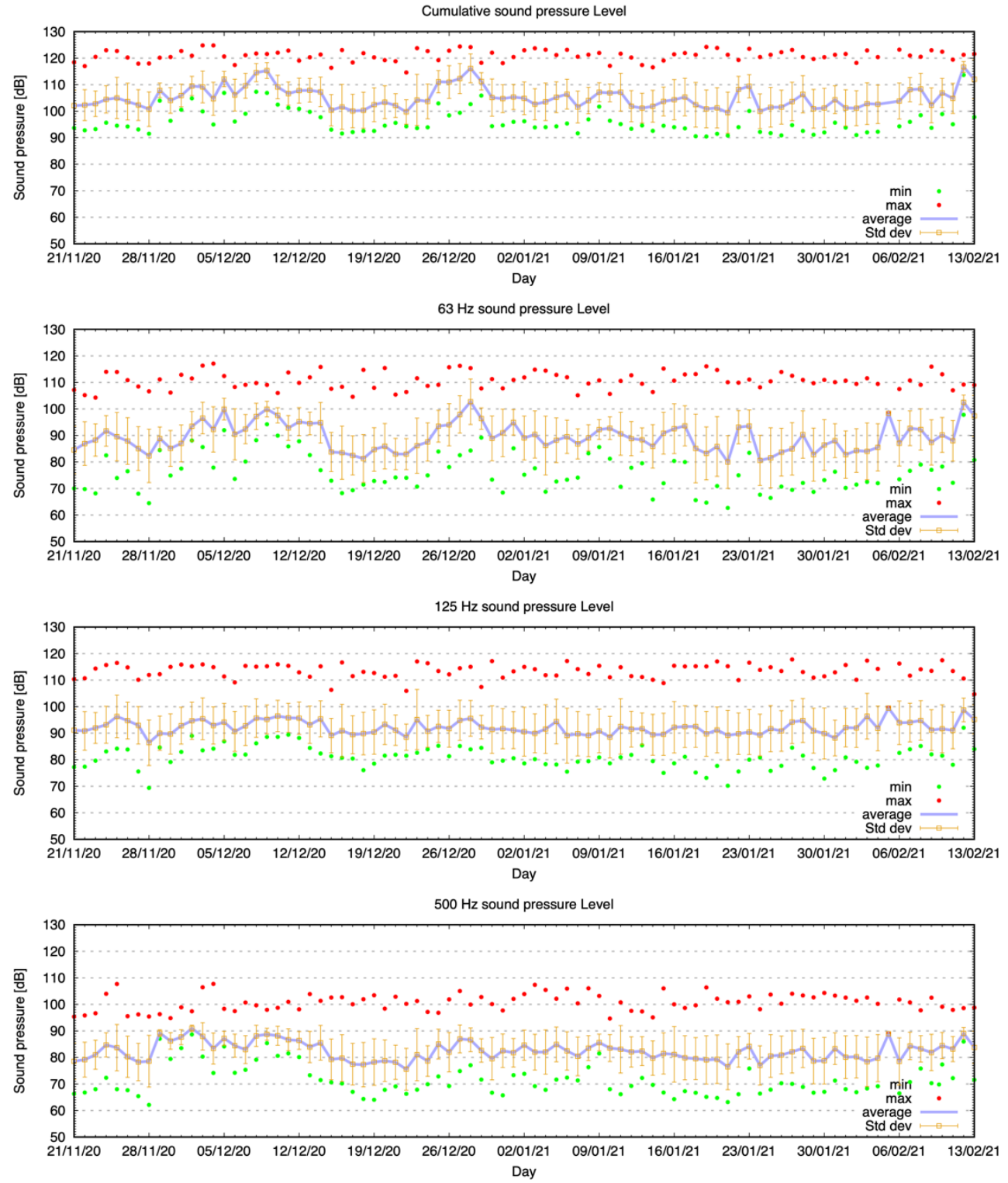

Figure 11. Plot of the minimum (green dots), maximum (red dots), average value (purple line), and standard deviation (whiskers) of the SPL as a function of day in the range between 11/21/2020 to $13 / 2 / 2021$, and similarly for the 63,125 , and $500 \mathrm{~Hz}$ one-third octave bands.

\section{Discussion}

The main work on underwater noise in the area of the Gulf of Trieste is from Codarin and Piciulin [1]. They monitored the sea ambient noise through $15 \mathrm{~min}$ long recordings taken monthly on 12 predefined acoustic stations throughout a whole year. One of the recording stations (C121) was relatively close to the location of the Mambo buoy, where we installed the system, meaning that it would theoretically be possible to compare its values with those obtained from the low-cost system.

The wideband spectrum SPL levels of the low-cost system showed $105.19 \mathrm{~dB}$ average value with 7.19 standard deviation, which can be compared with the reference values of $128 \mathrm{~dB}$ and 5.8 standard deviation that can be found in [1] for the whole year dataset.

The $63 \mathrm{~Hz}$ band showed $89.34 \mathrm{~dB}$ average value with 9.35 standard deviation. The annual average values that can be found in [1] are $100.51 \mathrm{~dB}$ with a 6.4 standard deviation.

The $125 \mathrm{~Hz}$ band showed $92.08 \mathrm{~dB}$ average value with 8.03 standard deviation, while the annual average values in [1] are $103.8 \mathrm{~dB}$ with a 6.4 standard deviation. 
We have also plotted in Figure 11 the trend for the $500 \mathrm{~Hz}$ band which shows $82.34 \mathrm{~dB}$ average value with 7.5 standard deviation.

The differences between our results and those reported in [1] can be explained in light of the specific period we considered. In fact, our recordings took place during winter and for three months only. In the area of the C121 recording station and of the Mambo buoy, during the summer season, leisure boat traffic can be quite intense, while in the winter, this is at its minimum. In addition, our recordings were made during a period of COVID pandemics restrictions. According to [64], the reduction in maritime traffic due to such reasons could be estimated up to $20 \mathrm{~dB}$ of reduction in SPL levels.

In Figure 12, it is possible to see a candlestick graph that shows the range of SPL values together with first and third quartiles (lower and upper limits of the box) as a function of each day in the designated period of the recordings. It is rather evident that SPL daily values do not follow a symmetrical bell-shaped pattern. They are instead skewed toward lower values.

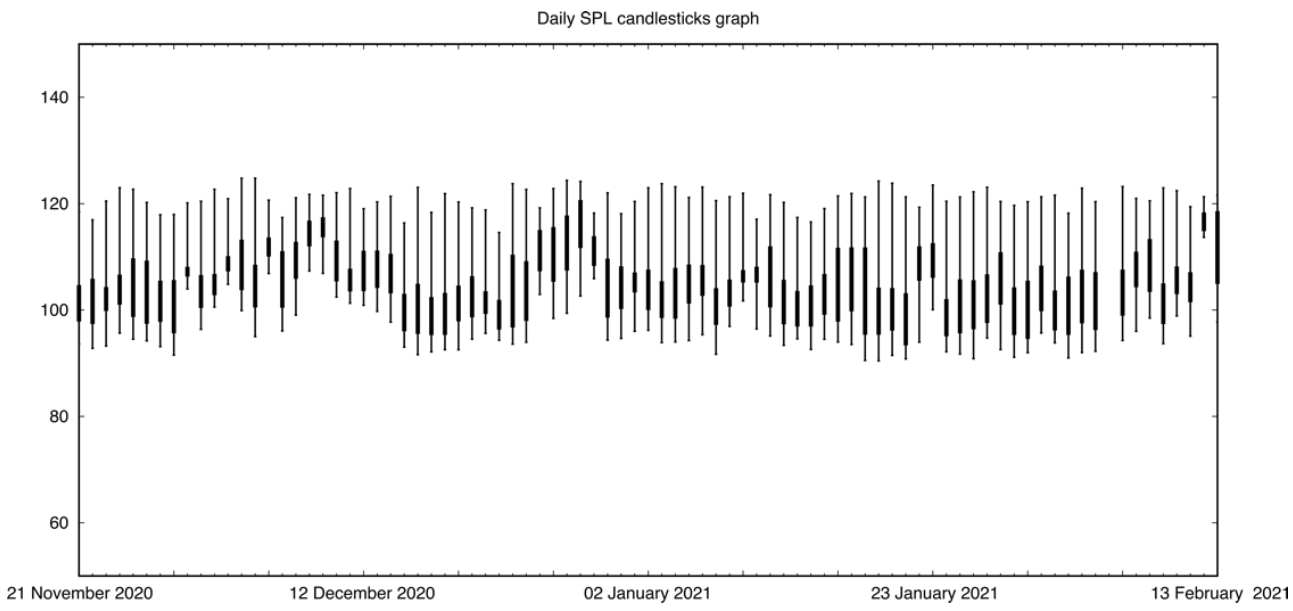

Figure 12. Candlestick graph showing the range of SPL values (whiskers) and the first and third quartile of the time series occurring throughout each day (box). It is possible to see that the distribution of SPL during the day is not symmetrical and bell shaped.

Figure 13 shows that high SPL levels (above $110 \mathrm{~dB}$ ) are confined above the 95th percentiles, meaning that they can be interpreted as transients or short duration events.

To understand the causes of the behaviors shown in Figures 12 and 13, we first tried to highlight any possible periodicity in the recordings applying an autocorrelation to the time series. The results can be seen in Figure 14. The graph shows on the abscissa the lag of the autocorrelation that is calculated as an index times $10 \mathrm{~min}$ of recording. In the detail, $6(\times 10 \mathrm{~min}) \times 24=144$ lag units correspond to a day, while 1008 lag units correspond to a week. The graphs show very good correlation with peaks corresponding to circadian trends and a rather evident weekly trend. Of course, it is not possible at this point to highlight longer or seasonal trends since the data under analysis only cover three months.

Given the fact that periodicities can be traced in the data, we tried further to highlight these trends in the time series.

We plotted the heat maps [65] of the SPL at various one-third octave bands (Figure 15) and discovered that especially at $125 \mathrm{~Hz}$ throughout all recordings, in a rather restricted range of time between 5 a.m. and 6 a.m., there is a distinct boost in SPL levels. Higher SPL levels are also recorded in the evening, although this is less clearly delimited in time.

It is rather straightforward to link these signals to fishing boats.

To highlight other kinds of temporal patterns, we focused on abiotic sounds such as winds and waves. According to $[66,67]$, the wind contribution should extend throughout all the spectrum recorded in this work, while surface waves cause mostly infrasonic noise at frequencies from 10 to $100 \mathrm{~Hz}$. 
It must be noted that the Gulf of Trieste is often swept in winter by a very strong Bora wind (NNE). The Bora wind is the strongest, most frequent, and persistent over the northeastern Adriatic [68] region, characterized by the formation of alternating jets and wakes associated with the coastal orography.

As a first test, we therefore compared the time series from wind speed and direction recorded daily in the port of Trieste with the SPL time series (Figures 16 and 17).
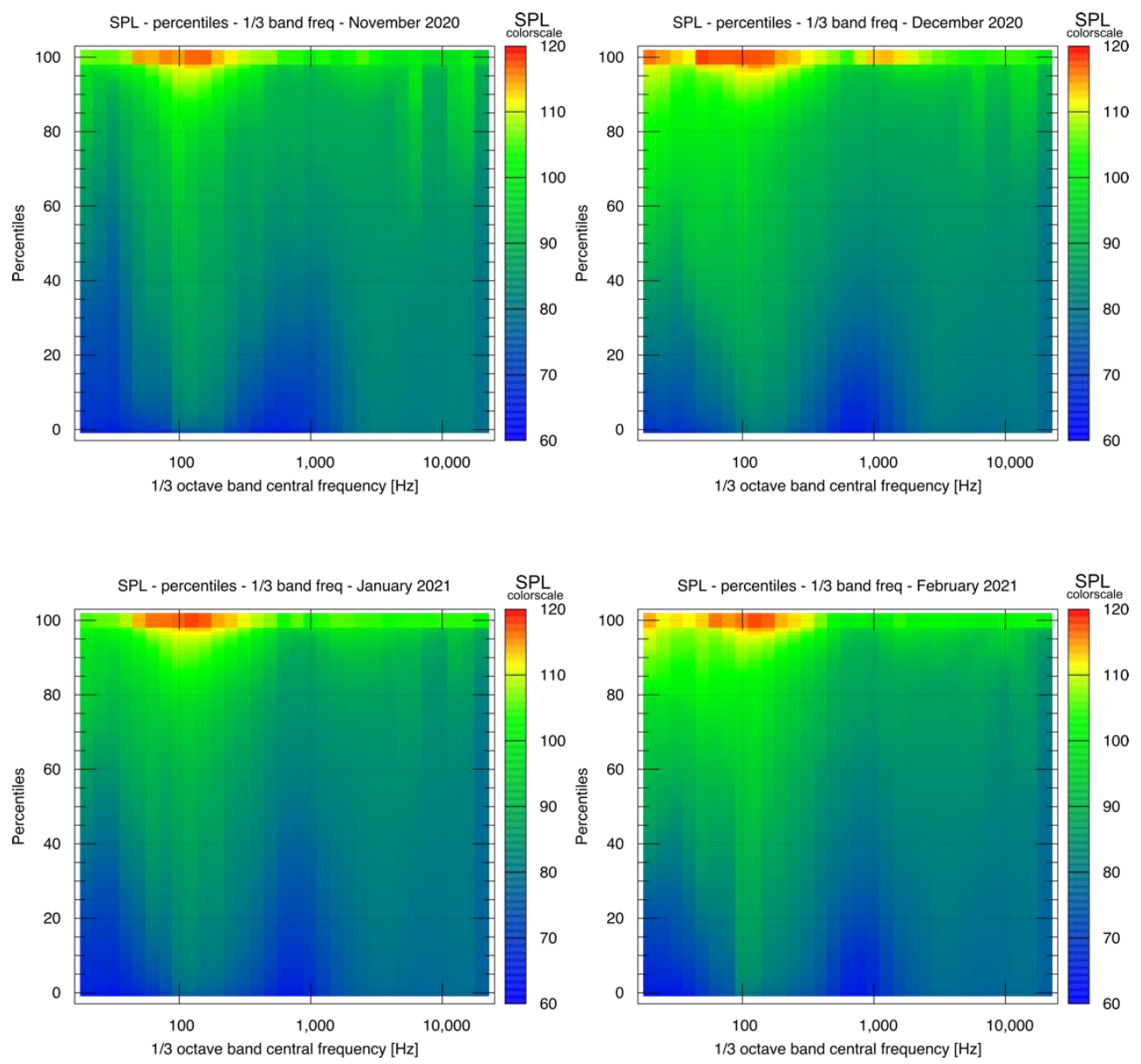

Figure 13. Percentiles versus the one-third octave band central frequency plot of SPL levels in the range between $60 \mathrm{~dB}$ and $120 \mathrm{~dB}$.

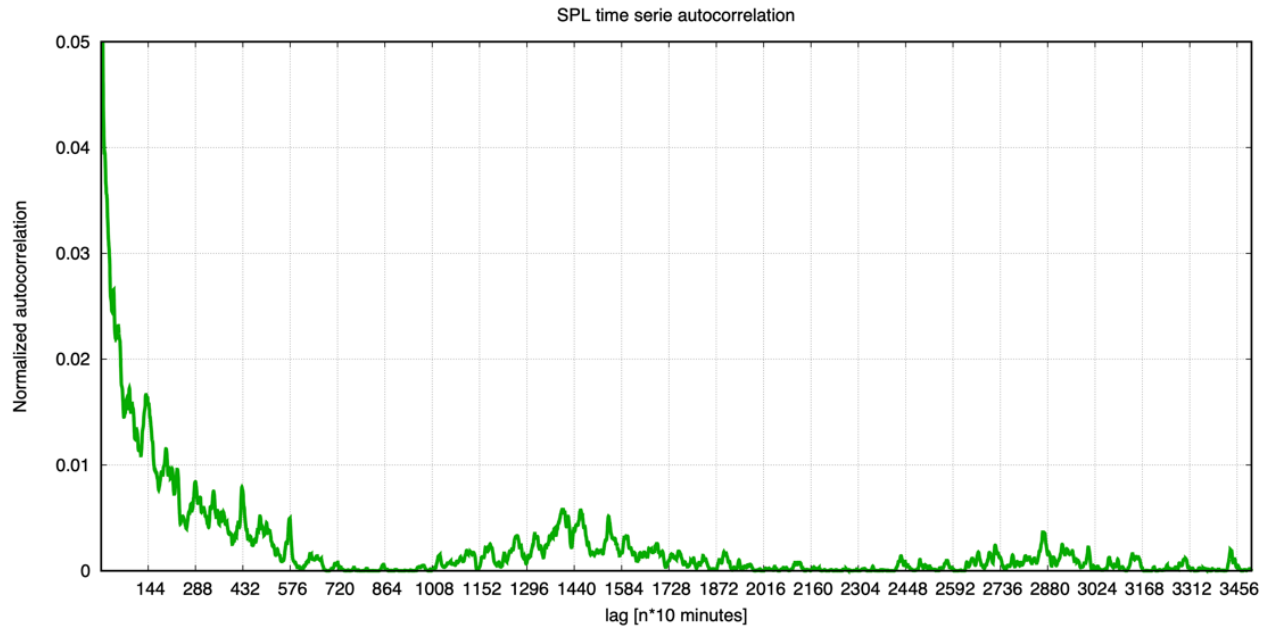

Figure 14. Autocorrelation of the cumulative SPL during the period 11/21/2020 and 2/13/2021. 
$125 \mathrm{~Hz}-\mathrm{dB}$ as a function of day and time

$\begin{array}{llllllllllllllllll}5 & 10 & 15 & 20 & 25 & 30 & 35 & 40 & 45 & 50 & 55 & 60 & 65 & 70 & 75 & 80 & 85 & 90\end{array}$

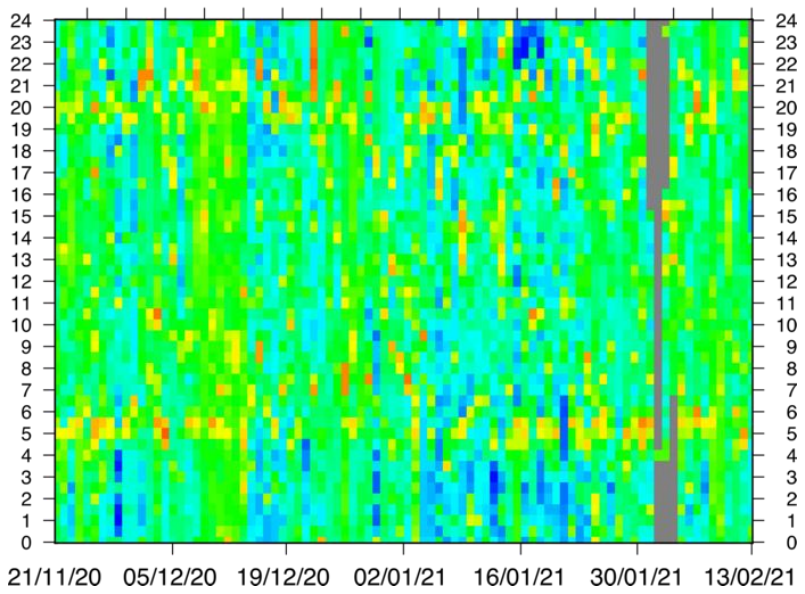

Figure 15. Heat maps that show the distribution of SPL for the $125 \mathrm{~Hz}$ one-third octave band as a function of the hour of the day versus day during the period 21 November 2020 and 13 February 2021. It is easy to recognize that in the morning (between 5 a.m. and 6 a.m.) there are high SPL values, probably due to the presence of fishing boats. Higher values can be found also between 7 p.m. and 10 p.m., but they are more spread in time.
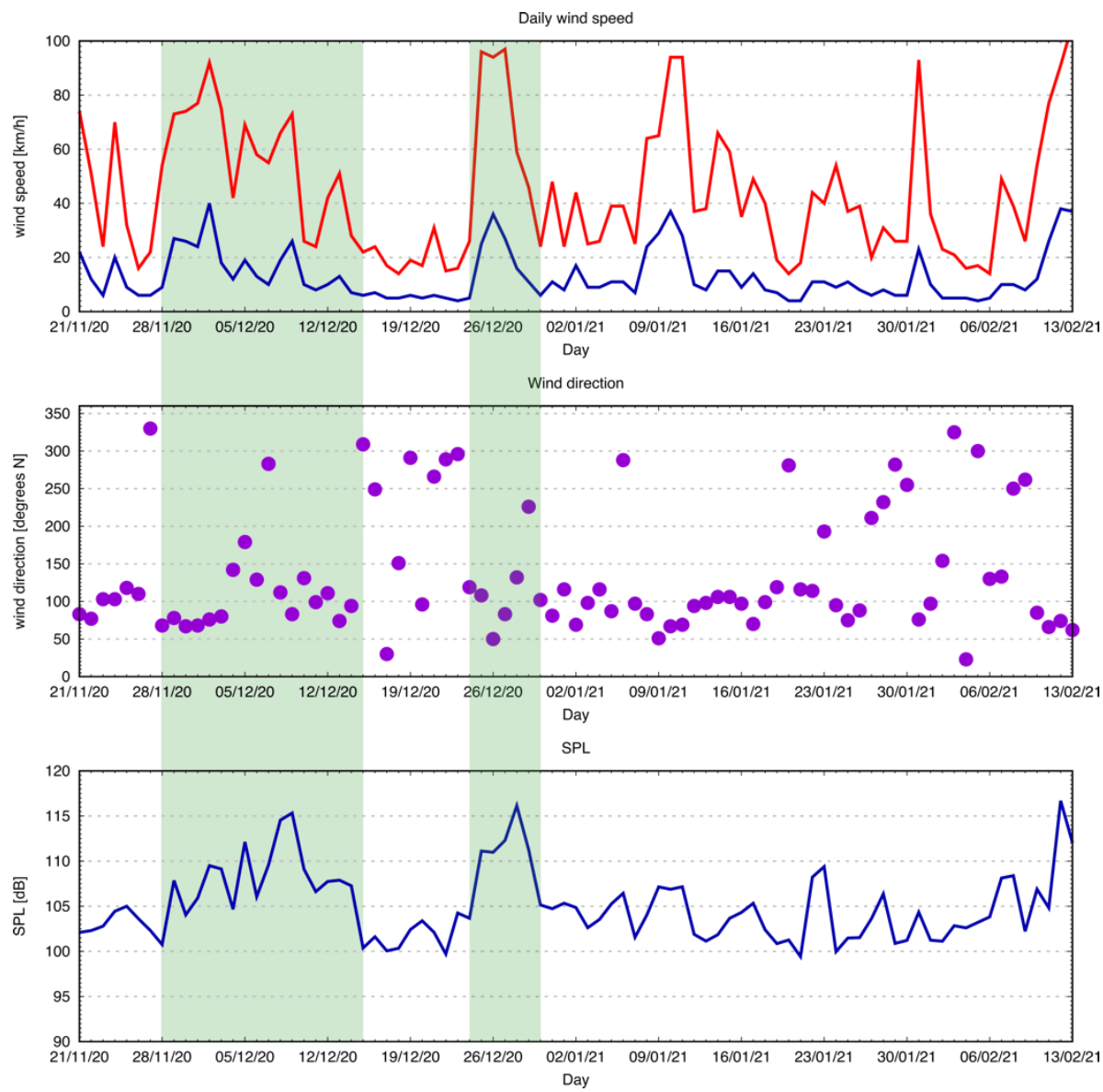

Figure 16. Time series correlation of wind and SPL. Some periods seem to be correlated (green areas), while not all periods of strong wind result in increased SPL. 


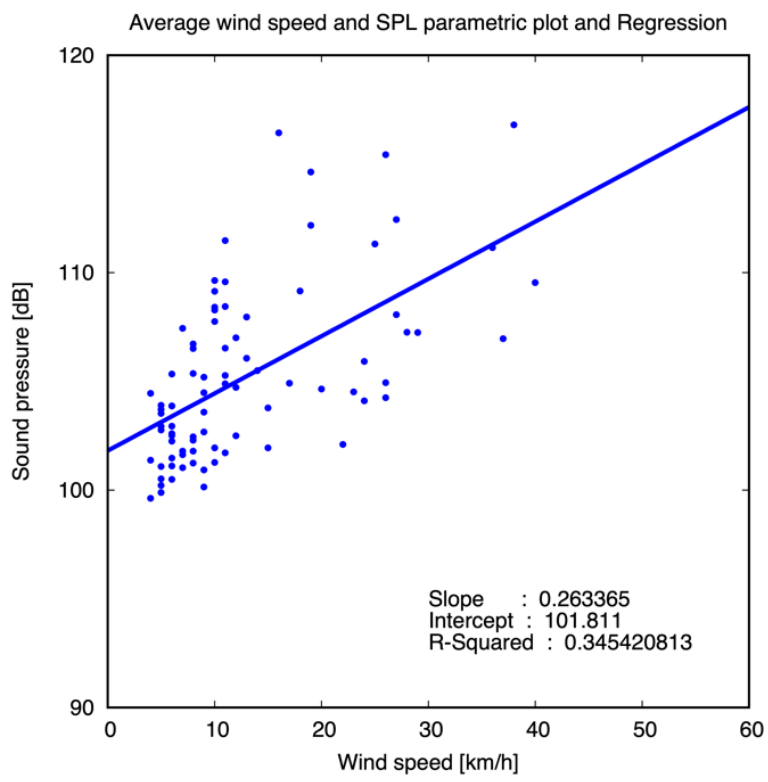

Figure 17. Parametric plot (SPL/wind speed) showing linear regression an R-squared factor.

Qualitative correlations can be found (in green in Figure 16), although not all windy periods correspond to distinct increases in SPL. A more quantitative result can be obtained from a parametric plot (SPL versus wind speed, Figure 17), where a linear regression of data points provides an R-squared factor of 0.34 .

\section{Conclusions}

This work demonstrated that low-cost and real-time PAM systems can be useful in assessing underwater noise in the perspective drawn by the MSDF. We highlighted the intrinsic limitations of the system, how we overcame them, and the possibilities that the system can offer reporting on an installation of the system that took place on the OGS MAMBO-1 buoy in the Gulf of Trieste (Northern Adriatic Sea). We demonstrated that this approach can be extended to consider a wider range of frequencies useful for example in bioacoustic studies, and in this perspective, we were able to record and identify several abiotic and anthropogenic temporal patterns.

The need behind the development of a low-cost PAM system is rooted in multiple considerations. They can be used to validate numeric models of the URN acoustic field over large areas deploying multiple simultaneous installations but at the same time without exceeding in costs. They can be used also where large investments are in general not possible, such as for example in developing countries. Being a system based on off-theshelf hardware and open-source software, it can be easily improved or extended, and in fact, the adoption of open-source software enabled us to develop a portal where time series from the system installed on the OGS MAMBO-1 buoy can be visualized, accessed, and heard. Other data products, such as for example spectrograms, can be visualized in real time, and new functionalities will be implemented in the future.

Author Contributions: Conceptualization, P.D.; Methodology, P.D., A.N. and M.I.; Software, M.I., R.C., N.P. and M.G.; Validation, M.B.; Resources, N.P., A.B. and F.B.; Data curation, M.B., L.G. and A.V.; Writing-original draft preparation, P.D.; Funding acquisition, P.D. and A.N. All authors have read and agreed to the published version of the manuscript.

Funding: This research was funded by POR FESR 2014-2020. Attività 1.3.b. DGR n. 1489/2017 (come modificato con decreto n. 12337/LAVFORU del 20/12/2017). Pratica n. 40145/2017 of the Italian Region Friuli Venezia Giulia.

Institutional Review Board Statement: Not applicable.

Informed Consent Statement: Not applicable. 
Data Availability Statement: All data used in this work can be accessed at the following link: https: / / corma.inogs.it (accessed on 6 April 2021). The portal shows real-time one-third octave band spectra obtained from recordings made with the developed system. Recordings and spectrograms can be downloaded only after acceptance of registration to the portal.

Acknowledgments: We would like to thank Cergol Engineering for having lent and operated the proprietary acquisition system used in the comparisons of Section 3.1 and Raphaela Gutty and Elizabeth Gergolet for their help throughout the project.

Conflicts of Interest: The authors declare no conflict of interest. The funders had no role in the design of the study; in the collection, analyses, or interpretation of data; in the writing of the manuscript, or in the decision to publish the results.

\section{References}

1. Codarin, A.; Picciulin, M. Underwater noise assessment in the Gulf of Trieste (Northern Adriatic Sea, Italy) using an MSFD approach. Mar. Pollut. Bull. 2015, 101, 694-700. [CrossRef] [PubMed]

2. Chou, E.; Southall, B.L.; Robards, M.; Rosenbaum, H.C. International policy, recommendations, actions and mitigation efforts of anthropogenic underwater noise. Ocean Coast. Manag. 2021, 202, 105427. [CrossRef]

3. European Parliament and Council. Directive 2008/56/EC of the European Parliament and of the Council of 17 June 2008 Establishing a Framework for Community Action in the Field of Marine Environmental Policy (Marine Strategy Framework Directive) (Text with EEA Relevance). 2008. Available online: https:// eur-lex.europa.eu/legal-content/EN/TXT/?uri=CELEX: 32008 L0056 (accessed on 6 April 2021).

4. Popper, A.; Hastings, M. The effects of anthropogenic sources of sound on fishes. J. Fish Biol. 2009, 75, 455-489. [CrossRef] [PubMed]

5. Boehlert, G.; Gill, A. Environmental and Ecological Effects of Ocean Renewable Energy Development-A Current Synthesis. Oceanography 2010, 23, 68-81. [CrossRef]

6. Sarà, G.; Dean, J.M.; D’Amato, D.; Buscaino, G.; Oliveri, A.; Genovese, S.; Ferro, S.; Buffa, G.; Lo Martire, M.; Mazzola, S. Marine Ecology Progress Series 331:243. Mar. Ecol. Prog. Ser. 2007, 331, 243-253. [CrossRef]

7. Thomsen, F.; Campbell, J.; Fredheim, B.; Unger, S.; Ashe, S.; Middleton, B. Overview of the Impacts of Anthropogenic Underwater Sound in the Marine Environment. OSPAR Commission Report. 2009. Available online: https://www.ospar.org/documents?v= 7147 (accessed on 6 April 2021).

8. Vasconcelos, R.O.; Amorim, M.C.P.; Ladich, F. Effects of ship noise on the detectability of communication signals in the Lusitanian toadfish. J. Exp. Biol. 2007, 210, 2104-2112. [CrossRef]

9. Codarin, A.; Wysocki, L.E.; Ladich, F.; Picciulin, M. Effects of ambient and boat noise on hearing and communication in three fish species living in a marine protected area (Miramare, Italy). Mar. Pollut. Bull. 2009, 58, 1880-1887. [CrossRef]

10. Hawkins, A.D. Examining Fish in the Sea: A European Perspective on Fish Hearing Experiments. In Perspectives on Auditory Research; Popper, A.N., Fay, R.R., Eds.; Springer: New York, NY, USA, 2014; Volume 50, pp. 247-267.

11. Robinson, S.P.; Wang, L.; Cheong, S.-H.; Lepper, P.A.; Marubini, F.; Hartley, J.P. Underwater acoustic characterisation of unexploded ordnance disposal using deflagration. Mar. Pollut. Bull. 2020, 160, 111646. [CrossRef]

12. Hawkins, A.D.; Popper, A.N. A sound approach to assessing the impact of underwater noise on marine fishes and invertebrates. ICES J. Mar. Sci. 2016, 74, 635-651. [CrossRef]

13. Southall, B.L.; Finneran, J.J.; Reichmuth, C.; Nachtigall, P.E.; Ketten, D.R.; Bowles, A.E.; Ellison, W.T.; Nowacek, D.P.; Tyack, P.L. Marine Mammal Noise Exposure Criteria: Updated Scientific Recommendations for Residual Hearing Effects. Aquat. Mamm. 2019, 45, 125-232. [CrossRef]

14. Hildebrand, J.A. Anthropogenic and natural sources of ambient noise in the ocean. Mar. Ecol. Prog. Ser. 2009, 395, 5-20. [CrossRef]

15. Erbe, C.; Reichmuth, C.; Cunningham, K.; Lucke, K.; Dooling, R. Communication masking in marine mammals: A review and research strategy. Mar. Pollut. Bull. 2016, 103, 15-38. [CrossRef] [PubMed]

16. Tasker, M.L. Overview of regulations for the conservation and protection of organisms in European seas. Bioacoustics 2008, 17, 280-283. [CrossRef]

17. Matthews, M.-N.R.; Ireland, D.S.; Zeddies, D.G.; Brune, R.H.; Pyć, C.D. A Modeling Comparison of the Potential Effects on Marine Mammals from Sounds Produced by Marine Vibroseis and Air Gun Seismic Sources. J. Mar. Sci. Eng. 2020, 9, 12. [CrossRef]

18. Løkkeborg, S.; Ona, E.; Vold, A.; Salthaug, A. Sounds from seismic air guns: Gear- and species-specific effects on catch rates and fish distribution. Can. J. Fish. Aquat. Sci. 2012, 69, 1278-1291. [CrossRef]

19. Mooney, A.; Andersson, M.; Stanley, J. Acoustic Impacts of Offshore Wind Energy on Fishery Resources: An Evolving Source and Varied Effects across a Wind Farm's Lifetime. Oceanography 2020, 33, 82-95. [CrossRef]

20. Halvorsen, M.B. Effects of Tidal Turbine Noise. p. 42. Available online: http:/ / ww.ntis.gov / ordering.htm (accessed on 8 February 2021).

21. Spandonidis, C.C.; Arvaniti, K. Numerical Modeling of the Exposure on Radiofrequency Radiation of Marine Mammal Observers during Their Shift: A Case Study. Int. J. Saf. Secur. Eng. 2020, 10, 753-758. [CrossRef]

22. Erbe, C.; Marley, S.A.; Schoeman, R.P.; Smith, J.N.; Trigg, L.E.; Embling, C.B. The Effects of Ship Noise on Marine Mammals-A Review. Front. Mar. Sci. 2019, 6. [CrossRef] 
23. Frisk, G.V. Noiseonomics: The relationship between ambient noise levels in the sea and global economic trends. Sci. Rep. 2012, 2, 437. [CrossRef]

24. Worldwide Ship Traffic up 300 Percent Since 1992, AGU Newsroom. Available online: https://news.agu.org/press-release/ worldwide-ship-traffic-up-300-percent-since-1992/ (accessed on 8 February 2021).

25. McDonald, M.A.; Hildebrand, J.A.; Wiggins, S.M.; Ross, D. A 50Year comparison of ambient ocean noise near San Clemente Island: A bathymetrically complex coastal region off Southern California. J. Acoust. Soc. Am. 2008, 124, 1985-1992. [CrossRef]

26. Veirs, S.; Veirs, V.; Wood, J.D. Ship noise extends to frequencies used for echolocation by endangered killer whales. PeerJ 2016, 4, e1657. [CrossRef]

27. Trevorrow, M.V.; Vasiliev, B.; Vagle, S. Directionality and maneuvering effects on a surface ship underwater acoustic signature. J. Acoust. Soc. Am. 2008, 124, 767-778. [CrossRef]

28. Hovem, J.M. Ray Trace Modeling of Underwater Sound Propagation. In Modeling and Measurement Methods for Acoustic Waves and for Acoustic Microdevices; Beghi, M.G., Ed.; InTech: London, UK, 2013. [CrossRef]

29. International Convention for the Safety of Life at Sea (SOLAS). 1974. Available online: https://www.imo.org/en/About/ Conventions/Pages/International-Convention-for-the-Safety-of-Life-at-Sea-(SOLAS),-1974.aspx (accessed on 19 February 2021).

30. Van der Graaf, A.J.; Ainslie, M.A.; André, M.; Brensing, K.; Dalen, J.; Dekeling, R.P.A.; Robinson, S.; Tasker, M.L.; Thomsen, F.; Werner, S. European Marine Strategy Framework Directive Good Environmental Status (MSFD-GES) Report of the Technical Sub-group on Underwater Noise and other forms of energy. EC 2012. Available online: https: / circabc.europa.eu/sd/a / 4c365582ff92-42d0-bf25-0f30e1f9c1db/MSFD\%20Final\%20report\%20of\%20the\%20TSG\%20Noise\%20feb2012.pdf (accessed on 6 April 2021).

31. Lara, G.; Miralles, R.; Bou-Cabo, M.; Esteban, J.A.; Espinosa, V. New Insights into the Design and Application of a Passive Acoustic Monitoring System for the Assessment of the Good Environmental Status in Spanish Marine Waters. Sensors 2020, 20, 5353. [CrossRef] [PubMed]

32. Van Parijs, S.M.; Clark, C.W.; Sousa-Lima, R.S.; Parks, S.E.; Rankin, S.; Risch, D.; Van Opzeeland, I.C. Management and research applications of real-time and archival passive acoustic sensors over varying temporal and spatial scales. Mar. Ecol. Prog. Ser. 2009, 395, 21-36. [CrossRef]

33. Hayes, S.A.; Mellinger, D.K.; Croll, D.A.; Costa, D.P.; Borsani, J.F. An inexpensive passive acoustic system for recording and localizing wild animal sounds. J. Acoust. Soc. Am. 2000, 107, 3552-3555. [CrossRef] [PubMed]

34. Pieretti, N.; Martire, M.L.; Corinaldesi, C.; Musco, L.; Dell'Anno, A.; Danovaro, R. Anthropogenic noise and biological sounds in a heavily industrialized coastal area (Gulf of Naples, Mediterranean Sea). Mar. Environ. Res. 2020, 159, 105002. [CrossRef] [PubMed]

35. Wiggins, S.M.; Hildebrand, J.A. High-frequency Acoustic Recording Package (HARP) for broad-band, long-term marine mammal monitoring. In Proceedings of the 2007 Symposium on Underwater Technology and Workshop on Scientific Use of Submarine Cables and Related Technologies, Tokyo, Japan, 17-20 April 2007; IEEE: Piscataway, NJ, USA, 2007; pp. 551-557.

36. Haver, S.M.; Gedamke, J.; Hatch, L.T.; Dziak, R.P.; Van Parijs, S.; McKenna, M.F.; Barlow, J.; Berchok, C.; DiDonato, E.; Hanson, B.; et al. Monitoring long-term soundscape trends in U.S. Waters: The NOAA/NPS Ocean Noise Reference Station Network. Mar. Policy 2018, 90, 6-13. [CrossRef]

37. Moran, K.; Boutin, B.; Juniper, S.K.; Pirenne, B.; Round, A. A multi-use and multi-stakeholder ocean observing platform system. In Proceedings of the OCEANS 2019 MTS/IEEE SEATTLE, Seattle, WA, USA, 27-31 October 2019; IEEE: Piscataway, NJ, USA, 2019; pp. 1-5.

38. Adam, O.; Glotin, H. Passive acoustic storey of the Antares neutrino detector for real-time cetaceans detection, localization and behavior studies. In Proceedings of the $2008 \mathrm{New}$ Trends for Environmental Monitoring Using Passive Systems, Hyeres, France, 14-17 October 2008; Institute of Electrical and Electronics Engineers (IEEE): Piscataway, NJ, USA, 2008; pp. 1-6.

39. Favali, P.; Chierici, F.; Marinaro, G.; Giovanetti, G.; Azzarone, A.; Beranzoli, L.; De Santis, A.; Embriaco, D.; Monna, S.; Bue, N.L.; et al. NEMO-SN1 Abyssal Cabled Observatory in the Western Ionian Sea. IEEE J. Ocean. Eng. 2013, 38, 358-374. [CrossRef]

40. Sanguineti, M.; Alessi, J.; Brunoldi, M.; Cannarile, G.; Cavalleri, O.; Cerruti, R.; Falzoi, N.; Gaberscek, F.; Gili, C.; Gnone, G.; et al. An automated passive acoustic monitoring system for real time sperm whale (Physeter macrocephalus) threat prevention in the Mediterranean Sea. Appl. Acoust. 2021, 172, 107650. [CrossRef]

41. Hu, C.; Pu, Y.; Yang, F.; Zhao, R.; Alrawais, A.; Xiang, T. Secure and Efficient Data Collection and Storage of IoT in Smart Ocean. IEEE Internet Things J. 2020, 7, 9980-9994. [CrossRef]

42. Climent, S.; Sanchez, A.; Capella, J.V.; Meratnia, N.; Serrano, J.J. Underwater Acoustic Wireless Sensor Networks: Advances and Future Trends in Physical, MAC and Routing Layers. Sensors 2014, 14, 795-833. [CrossRef] [PubMed]

43. Ajemian, M.J.; Lamboy, C.; Ibrahim, A.; DeGroot, B.C.; Bassos-Hull, K.; Mann, D.A.; Chérubin, L. Capturing shell-crushing by large mobile predators using passive acoustics technology. J. Exp. Mar. Biol. Ecol. 2021, 535, 151497. [CrossRef]

44. SoX. Available online: http:/ / sox.sourceforge.net/sox.html (accessed on 16 March 2021).

45. Cibic, T.; Franzo, A.; Nasi, F.; Auriemma, R.; Del Negro, P. The Port of Trieste (Northern Adriatic Sea)—A Case Study of the "Ecosystem Approach to Management. Front. Mar. Sci. 2017, 4. [CrossRef]

46. Cosoli, S.; Ličer, M.; Vodopivec, M.; Malačič, V. Surface circulation in the Gulf of Trieste (northern Adriatic Sea) from radar, model, and ADCP comparisons. J. Geophys. Res. Oceans 2013, 118, 6183-6200. [CrossRef] 
47. Cozzi, S.; Falconi, C.; Comici, C.; Čermelj, B.; Kovac, N.; Turk, V.; Giani, M. Recent evolution of river discharges in the Gulf of Trieste and their potential response to climate changes and anthropogenic pressure. Estuar. Coast. Shelf Sci. 2012, 115, 14-24. [CrossRef]

48. Ogorelec, B.; Mišič, M.; Faganeli, J. Marine geology of the Gulf of Trieste (northern Adriatic): Sedimentological aspects. Mar. Geol. 1991, 99, 79-92. [CrossRef]

49. Trobec, A.; Busetti, M.; Zgur, F.; Baradello, L.; Babich, A.; Cova, A.; Gordini, E.; Romeo, R.; Tomini, I.; Poglajen, S.; et al. Thickness of marine Holocene sediment in the Gulf of Trieste (northern Adriatic Sea). Earth Syst. Sci. Data 2018, 10, 1077-1092. [CrossRef]

50. Falcieri, F.M.; Kantha, L.; Benetazzo, A.; Bergamasco, A.; Bonaldo, D.; Barbariol, F.; Malačič, V.; Sclavo, M.; Carniel, S. Turbulence observations in the Gulf of Trieste under moderate wind forcing and different water column stratification. Ocean Sci. 2016, 12, 433-449. [CrossRef]

51. Picciulin, M.; Bolgan, M.; Codarin, A.; Fiorin, R.; Zucchetta, M.; Malavasi, S. Passive acoustic monitoring of Sciaena umbra on rocky habitats in the Venetian littoral zone. Fish. Res. 2013, 145, 76-81. [CrossRef]

52. Genov, T.; Kotnjek, P.; Centrih, T. Occurrence of common dolphins (Delphinus delphis) in the Gulf of Trieste and the northern Adriatic Sea. Aquat. Conserv. Mar. Freshw. Ecosyst. 2020. [CrossRef]

53. Kralj, M.; Lipizer, M.; Čermelj, B.; Celio, M.; Fabbro, C.; Brunetti, F.; Francé, J.; Mozetič, P.; Giani, M. Hypoxia and dissolved oxygen trends in the northeastern Adriatic Sea (Gulf of Trieste). Deep. Sea Res. Part II Top. Stud. Oceanogr. 2019, 164, 74-88. [CrossRef]

54. Welch, P. The use of fast Fourier transform for the estimation of power spectra: A method based on time averaging over short, modified periodograms. IEEE Trans. Audio Electroacoust. 1967, 15, 70-73. [CrossRef]

55. Diviacco, P.; Firetto Carlino, M.; Busato, A. Enhancing the value of public vintage seismic data in the Italian offshore. Geosci. Data J. 2019, 6, 6-15. [CrossRef]

56. Diviacco, P. On formalization and representation in collaborative research. In Dynamic Knowledge Representation in Scientific Domains; IGI Global: Hershey, PA, USA, 2018; pp. 89-97. [CrossRef]

57. CORMA. Available online: https:/ / corma.inogs.it (accessed on 28 March 2021).

58. IEC 60565-1:2020 I IEC Webstore. Available online: https://webstore.iec.ch/publication/32074 (accessed on 4 March 2021).

59. Slater, W.H.; Crocker, S.E.; Baker, S.R. A primary method for the complex calibration of a hydrophone from $1 \mathrm{~Hz}$ to $2 \mathrm{kHz}$. Metrologia 2017, 55, 84-94. [CrossRef]

60. Theobald, P.D.; Robinson, S.P.; Thompson, A.D.; Preston, R.C.; Lepper, P.A.; Yuebing, W. Technique for the calibration of hydrophones in the frequency range 10 to $600 \mathrm{kHz}$ using a heterodyne interferometer and an acoustically compliant membrane. J. Acoust. Soc. Am. 2005, 118, 3110-3116. [CrossRef]

61. Robinson, S.P.; Theobald, P.D.; Foote, K.G. Calibration of hydrophones and electroacoustic transducers: A contribution to the OES standards initiative. In Proceedings of the OCEANS 2014, Taipei, Taiwan, 7-10 April 2014; pp. 1-5. [CrossRef]

62. Benadí, A.G.; Cadena-Munoz, J.; Fernandez, J.D.R.; Juan, X.R.; Manuel-Làzaro, A. Good Practice Guide for calibrating a hydrophone "in situ" with a non-omnidirectional source at $10 \mathrm{kHz}$. Acta IMEKO 2015, 4, 26. [CrossRef]

63. ISO. ISO/PAS 19450:2015: Automation Systems and Integration-Object-Process Methodology. Available online: https://www. iso.org/obp/ui/\#iso:std:iso:pas:19450:ed-1:v1:en (accessed on 6 April 2021).

64. Leon-Lopez, B.; Romero-Vivas, E.; Viloria-Gomora, L. Reduction of roadway noise in a coastal city underwater soundscape during COVID-19 confinement. J. Acoust. Soc. Am. 2021, 149, 652-659. [CrossRef]

65. Miralles, R.; Lara, G.; Gosalbez, J.; Bosch, I.; León, A. Improved visualization of large temporal series for the evaluation of good environmental status. Appl. Acoust. 2019, 148, 55-61. [CrossRef]

66. Buscaino, G.; Ceraulo, M.; Pieretti, N.; Corrias, V.; Farina, A.; Filiciotto, F.; Maccarrone, V.; Grammauta, R.; Caruso, F.; Alonge, G.; et al. Temporal patterns in the soundscape of the shallow waters of a Mediterranean marine protected area. Sci. Rep. 2016, 6, 34230. [CrossRef]

67. Haxel, J.H.; Dziak, R.P.; Matsumoto, H. Observations of shallow water marine ambient sound: The low frequency underwater soundscape of the central Oregon coast. J. Acoust. Soc. Am. 2013, 133, 2586-2596. [CrossRef]

68. Vozila, A.B.; Güttler, I.; Ahrens, B.; Obermann-Hellhund, A.; Prtenjak, M.T. Wind Over the Adriatic Region in CORDEX Climate Change Scenarios. J. Geophys. Res. Atmos. 2019, 124, 110-130. [CrossRef] 